\title{
FORMAÇÃO DE PROFESSORES PARA ATUAR NO ENSINO SUPERIOR, TECNOLÓGICO E TÉCNICO
}

\author{
FORMACIÓN DE PROFESORES PARA ACTUAR EN LA ENSEÑANZA SUPERIOR, \\ TECNOLÓGICO Y TÉCNICO
}

\author{
TRAINING OF TEACHERS TO ACT IN HIGHER, TECHNOLOGICAL AND \\ TECHNICAL EDUCATION
}

Jacques de Lima FERREIRA ${ }^{1}$

Marilda Aparecida BEHRENS ${ }^{2}$

Alexandre Marinho TEIXEIRA ${ }^{3}$

RESUMO: Este artigo apresenta uma pesquisa de abordagem qualitativa do tipo estudo de caso que foi realizada com profissionais de diversas áreas do conhecimento, egressos que realizaram uma formação continuada, uma especialização denominada Formação de Professores, para atuar no Ensino Superior, Tecnológico e Técnico. O problema de pesquisa que orientou a investigação seguiu o seguinte questionamento: Quais são as percepções que os egressos de uma formação continuada tiveram sobre o conhecimento adquirido para o exercício da docência? A investigação realizada teve o objetivo de analisar as percepções dos egressos em relação ao conhecimento adquirido a partir de uma especialização para a formação de professores. A pesquisa envolveu 03 turmas da especialização dos seguintes anos: 2015, com 32 alunos; 2016, com 25 alunos e 2017, com 15 alunos, totalizando 72 alunos egressos investigados. Os dados foram coletados a partir de um questionário com perguntas abertas e fechadas que permitiram realizar a análise de conteúdo na perspectiva de Bardin (2011), com o auxílio do software Atlas Ti. A análise de dados permitiu identificar que o conhecimento pedagógico é essencial para poder vivenciar a docência diante da sua complexidade. Conhecimento este que permite que o professor possa estar em sala de aula para poder utilizar diferentes metodologias de ensino.

PALAVRAS-CHAVE: Formação de professores. Formação continuada. Conhecimento pedagógico.

RESUMEN: Este artículo presenta una investigación de abordaje cualitativo del tipo estudio de caso que fue realizado con profesionales de diversas áreas del conocimiento, egresados que realizaron una formación continuada, una especialización denominada Formación de Profesores para actuar en la Enseñanza Superior, Tecnológico y Técnico. El problema de investigación que orientó la investigación siguió el siguiente cuestionamiento: ¿Cuáles son las percepciones que los egresados de una formación continuada tuvieron sobre el

\footnotetext{
${ }^{1}$ Universidade Positivo (UP), Curitiba - PR - Brasil. Professor Universitário da Graduação e Pós-Graduação. Email: drjacqueslima@hotmail.com

${ }^{2}$ Pontifícia Universidade Católica do Paraná (PUCPR), Curitiba - PR - Brasil. Professora do Programa de PósGraduação em Educação. E-mail: marildaab@gmail.com

${ }^{3}$ Instituto Federal de Santa Catarina (IFSC), Gaspar - SC - Brasil. Professor na Graduação e Pós-Graduação em Administração. E-mail: alexandre.marinho@ifsc.edu.br
} 
conocimiento adquirido para el ejercicio de la docencia? La investigación realizada tuvo el objetivo de analizar las percepciones de los egresados en relación al conocimiento adquirido a partir de una especialización para la formación de profesores. La investigación involucró a tres grupos de la especialización de los siguientes años: 2015, con 32 alumnos; 2016, con 25 alumnos y 2017, con 15 alumnos, totalizando 72 alumnos egresados investigados. Los datos fueron recolectados a partir de un cuestionario con preguntas abiertas y cerradas que permitieron realizar el análisis de contenido en la perspectiva de Bardin (2011) con la ayuda del software Atlas Ti. El análisis de datos permitió identificar que el conocimiento pedagógico es esencial para poder vivir la docencia ante su complejidad. Conocimiento que permite que el profesor pueda estar en el aula para poder utilizar diferentes metodologías de enseñanza.

PALABRAS-CLAVE: Formación de profesores. Formación continua. Conocimiento pedagógico.

ABSTRACT: This article presents a qualitative research of the type of case study that was carried out with professionals from several areas of knowledge, graduates who have carried out a continuous formation, a specialization denominated Training of Teachers to act in Higher Education, Technological and Technical. The research problem that guided the research followed the following question: What are the perceptions that graduates of a continuing formation had about the knowledge acquired for the exercise of teaching? The research carried out had the objective of analyzing the graduates perceptions in relation to the knowledge acquired from a specialization for the training of teachers. The research involved 03 specialization classes of the following years: 2015, with 32 students; 2016, with 25 students and 2017, with 15 students, totaling 72 students graduated. The data were collected from a questionnaire with open and closed questions that allowed the analysis of content from the perspective of Bardin (2011) with the help of Atlas Ti software. Data analysis allowed us to identify that pedagogical knowledge is essential to be able to experience teaching in the face of its complexity. Knowledge that allows the teacher to be in the classroom to be able to use different teaching methodologies.

KEYWORDS: Teacher training. Continuing education. Pedagogical knowledge.

\section{Introdução}

A educação no Brasil mudou muito nas últimas décadas, mudanças essas influenciadas pelas demandas sociais que buscam a democratização da educação e a inclusão dos alunos nos diferentes níveis e modalidades de ensino. O processo de democratização está também relacionado à formação dos professores, formação essa que se apresenta complexa e dinâmica, exigindo do formador e do futuro professor uma série de conhecimentos que são essenciais para a docência.

Os conhecimentos que são necessários para que um professor possa atuar hoje em sala de aula possibilitam uma série de discussões no campo da formação de professores, 
principalmente para os cursos de licenciaturas e para as instituições de ensino superior. A perspectiva epistemológica do formador de professores no que diz respeito à construção de conhecimento está intimamente relacionada à forma como os formadores planejam e realizam as suas práticas pedagógicas diante do processo de ensino e aprendizagem.

Ao compreender a formação de professores como um processo complexo que permite a construção de conhecimento teórico, metodológico e prático do trabalho docente, considerando que o conhecimento adquirido influencia a prática, a forma em que o professor planeja suas aulas, realiza a organização do currículo e suas demais ações pedagógicas.

Esta pesquisa de abordagem qualitativa, do tipo estudo de caso de natureza interpretativa, em seu problema de pesquisa busca responder a seguinte indagação: Quais são as percepções que os egressos de uma formação continuada tiveram sobre o conhecimento adquirido para o exercício da docência? A investigação realizada teve o objetivo de analisar as percepções dos egressos em relação ao conhecimento adquirido a partir de uma especialização para a formação de professores, com vistas a compreender melhor o processo de construção de conhecimento que os bacharéis tiveram, sendo que os mesmos não recebem formação pedagógica na graduação.

Deste modo, este estudo adota postulações de pesquisadores da área, como Saviani (1996), Tardif (2002), Pimenta (2002), Nóvoa (2009), Imbernón (2011), Ferreira (2014), entre outros, para apresentar considerações sobre a formação de professores e conhecimentos necessários à docência. Infere-se que os apontamentos resultantes deste estudo podem, seguindo a perspectiva de Creswell (2014), no que se refere a uma pesquisa do tipo estudo de caso, contribuir ao campo teórico investigado com o entendimento verticalizado sobre um assunto, o estudo de um caso, dentro de um processo em um contexto contemporâneo com suas particularidades.

Tendo em vista os itens tomados a partir das postulações de Creswell (2014), acreditase que os achados dessa pesquisa possam contribuir ao campo da formação de professores, tornando possível identificar quais conhecimentos são essenciais para formar um professor na visão de bacharéis, bem como colaborar com futuros processos formativos tanto na formação inicial e continuada de professores e as particularidades que envolvem o processo formativo.

Depreende-se, assim, que esta pesquisa pode permitir uma melhor compreensão do processo de formação de professores a partir do conhecimento construído pelo aluno que almeja a docência em diferentes níveis e modalidades de educação e ensino. A pesquisa envolveu 03 turmas da especialização denominada Formação de Professores para atuar no Ensino Superior, Tecnológico e Técnico, dos seguintes anos: 2015, com 32 alunos; 2016, com 
25 alunos e 2017, com 15 alunos, totalizando 72 alunos egressos investigados. Os dados utilizados nesta investigação advêm de um questionário com perguntas abertas e fechadas que permitiram realizar a Análise de Conteúdo (AC) na perspectiva de Bardin (2011) com o auxílio do software Atlas Ti.

$\mathrm{Na}$ próxima seção são apresentadas postulações teóricas acerca da formação de professores e do processo de construção de conhecimento para a formação docente.

\section{Conhecimentos necessários para a Formação de Professores}

O campo da formação de professores apresenta desafios que afetam diretamente o processo de ensino e aprendizagem e a qualidade da educação. Os enfrentamentos são inúmeros, não é possível eleger os principais, pois a formação de um professor é algo complexo. Ferreira (2014) enfatiza que a formação de um professor exige uma série de conhecimentos que se estabelecem nas relações humanas, epistemológicas, sociais, entre outras.

Durante o processo de formação docente várias adversidades podem ser encontradas, como: a desvalorização da carreira, as dificuldades de aprendizagem que o aluno apresenta, a dissociação entre teoria e prática, desigualdade social e cultural, deficiência na gestão e no currículo da formação docente, falta de infraestrutura e de tecnologia, formador com metodologia conservadora e uma formação mercadológica que não propicia o conhecimento da profissão e a produção de conhecimento.

Todas as dificuldades mencionadas dependem das políticas educacionais, do contexto social e econômico e, principalmente, do formador, da sua formação e da experiência em relacionar o conhecimento teórico com a prática e do conhecimento da prática profissional. Com o propósito de que a docência possa enfrentar esses desafios mencionados para a formação de um professor, é importante destacar que o processo formativo precisa fornecer o contato com a realidade das instituições de ensino. A realidade da sala de aula apresenta-se tão matizada que muitas vezes a teoria não dá conta de mediar a prática, o professor em formação necessita realizar estágio por mais tempo para poder conhecer e acompanhar a realidade da sala de aula.

Os professores, neste início do século XXI, apresentam-se “[...] como elementos insubstituíveis não só na promoção das aprendizagens, mas também na construção de processo de inclusão que respondam aos desafios da diversidade e no desenvolvimento de métodos apropriados para a utilização das novas tecnologias" (NÓVOA, 2009, p. 13). Ser 
professor demanda enfrentar as mudanças e as incertezas da educação, assim como os desafios impostos à carreira docente, pois "[...] a educação dos seres humanos pouco a pouco se tornou mais complexa, o mesmo deverá acontecer à profissão docente. Essa complexidade é incrementada pela mudança radical e vertiginosa das estruturas científicas, sociais e educativas [...]" (IMBERNÓN, 2011, p. 9).

O exercício da profissão envolve elementos que são advindos da sua formação e experiência, o que torna a sua prática pedagógica única. Dentro dos aspectos que definem a profissão docente, os conhecimentos que o professor utiliza para ensinar podem mudar ao longo da sua formação inicial e continuada. Autores como Tardif, Lessard e Lahaye (1991); Saviani (1996); Tardif e Gauthier (2001); Tardif (2002); Pimenta (2002); entre outros, chamam os conhecimentos do professor de saberes docentes. Cada autor apresenta uma visão sobre os conhecimentos necessários para a docência, que podem partir das competências que envolvem o seu trabalho até conhecimentos específicos da ação pedagógica, bem como o gerenciamento e o planejamento do conhecimento em forma de disciplinas e conteúdos.

Muitos pesquisadores estudam os conhecimentos que são necessários e que envolvem a formação docente e seu desenvolvimento profissional. Para exemplificar as diferentes denominações em relação aos conhecimentos necessários para a docência, Silva (2011, p. 76) apresenta as denominações utilizadas por diversos autores, conforme o Quadro 01.

Quadro 01 - Denominações utilizadas por diferentes autores para tratar dos conhecimentos necessários para a docência

\begin{tabular}{|l|l|}
\hline \multicolumn{1}{|c|}{ Autores } & \multicolumn{1}{c|}{ Denominações } \\
\hline Ken Shulman (1986) & $\begin{array}{l}\text { Conhecimento do conteúdo da matéria ensinada; } \\
\text { Conhecimento Pedagógico da matéria; Conhecimento } \\
\text { Curricular. }\end{array}$ \\
\hline $\begin{array}{l}\text { Maurice Tardif, Claude Lessard e Louise Lahaye } \\
\text { (1991) e Tardif (2002) }\end{array}$ & $\begin{array}{l}\text { Saberes profissionais (ciências da educação e ideologia } \\
\text { pedagógica); Saberes das disciplinas; Saberes } \\
\text { curriculares; Saberes da experiência. }\end{array}$ \\
\hline Dermeval Saviani (1996) & $\begin{array}{l}\text { Saber atitudinal; Saber crítico-contextual; Saberes } \\
\text { específicos, Saber pedagógico; Saber didático- } \\
\text { curricular. }\end{array}$ \\
\hline Clermont Gauthier (1998) & $\begin{array}{l}\text { Saber disciplinar; Saber curricular; Saber das ciências } \\
\text { da educação; Saber da tradição pedagógica; Saber } \\
\text { experiencial; Saber da ação pedagógica. }\end{array}$ \\
\hline Selma Garrido Pimenta (2002) & $\begin{array}{l}\text { Saberes da experiência; Saberes do conhecimento; } \\
\text { Saberes pedagógicos. }\end{array}$ \\
\hline $\begin{array}{l}\text { Philippe Perrenoud, Léopold Paquay, Marguerite } \\
\text { Altet, Évelyne Charlier (2001) }\end{array}$ & $\begin{array}{l}\text { Saber teóricos: saberes a serem ensinados, saberes para } \\
\text { ensinar; Saberes práticos: saberes sobre a prática, } \\
\text { saberes da prática. }\end{array}$ \\
\hline
\end{tabular}

Fonte: Silva (2011, p. 76) quadro adaptado pelos autores.

A partir do quadro apresentado, é possível identificar que a denominação saberes vem sendo utilizada por pesquisadores para se referir aos conhecimentos necessários à docência. 
Utilizamos a denominação conhecimento para facilitar o entendimento sobre o objeto de estudo deste artigo.

A formação de um professor é uma atividade sistematizada que permite fornecer informação e conhecimento teórico e prático específico da ação pedagógica, com o objetivo de preparar o docente para exercer a docência; isso requer uma série de conhecimentos que são fundamentais para a sua profissionalização.

A compreensão é de que existem diferentes pensamentos para entender o que um docente precisa saber para ser professor e exercer a profissão, como já mencionado, e que esses conhecimentos vão depender da formação recebida a partir das políticas educacionais, do contexto social e econômico, do formador e da instituição de ensino.

\section{Formação continuada para o exercício da docência}

A pesquisa desse artigo advém de uma formação continuada realizada na forma de uma especialização denominada: Formação de Professores para atuar no Ensino Superior, Tecnológico e Técnico, que acontece em uma grande Universidade particular. Essa especialização tem como objetivo o desenvolvimento e o aprofundamento de conhecimentos teórico-práticos pertinentes à docência no Ensino Superior, Tecnológico e Técnico e demais contextos de ação pedagógica em espaços presenciais ou online, enfatizando questões referentes à produção do conhecimento e ao ensino associado à investigação científica. A especialização oferece formação continuada para graduados de diferentes áreas do conhecimento que desejam habilitar-se ao magistério.

Nos cursos de bacharelado, os alunos são formados para exercer uma determinada profissão, sem conhecimentos para o exercício da docência. Os que almejam ingressar no magistério buscam por formação continuada para que possam obter conhecimentos teóricos e práticos necessários para torna-se professor dentro da sua área de formação. O processo formativo geralmente acontece como formação continuada Lato ou Stricto Sensu.

A especialização ofertada acontece a cada 15 dias e permite aos estudantes vivenciar a ambientação universitária, tecnológica e técnica em diferentes salas de aula, assistindo a aulas nos cursos onde o discente tem formação inicial e outros cursos, bem como observando diferentes metodologias dos professores. O curso apresenta um currículo inovador, estruturado na formação de professores, desenvolvimento profissional docente, tecnologias e no processo de ensino e aprendizagem. O corpo docente é formado por professores mestres e doutores com experiência na área. 
O currículo do curso apresenta disciplinas como: Profissão Professor; Ensino Superior, Tecnológico e Técnico: as Políticas Educacionais; Concepções Pedagógicas e Didáticas no Ensino Presencial e a Distância; Diversidade, Inclusão e Direitos Humanos; Aprendizagem e Andragogia; Tecnologias Educacionais e EAD; Currículo no Ensino Presencial e a Distância; Planejamento e Organização do Processo de Ensino-Aprendizagem: Presencial e a Distância; Avaliação da Aprendizagem, do Ensino e Institucional; Docência: Prática de Ensino; Metodologia da Pesquisa; Seminário de Pesquisa; Trabalho de Conclusão do Curso e Estágio Supervisionado.

\section{Percurso Metodológico da Pesquisa}

A investigação deste artigo buscou analisar as percepções dos egressos em relação ao conhecimento adquirido a partir de uma especialização para a formação de professores. Os egressos são bacharéis de diferentes áreas do conhecimento, como: Medicina, Direito, Engenharia, Enfermagem, Arquitetura, Administração, Economia, Desing, Gestão de Recursos Humanos, Gastronomia, Marketing, entro outras, que almejam a docência como profissão na área em que possuem formação inicial, seja ela superior ou tecnológica.

Para realizar essa pesquisa, a abordagem qualitativa do tipo estudo de caso de natureza interpretativa, foi escolhida, pois permite que o pesquisador interprete o fenômeno perante a sua realidade e seu entorno (CHIZZOTTI, 2006, p. 28). A investigação realizada é enriquecida por envolver uma pesquisa do tipo estudo de caso, por possibilitar a investigação detalhada de um caso, especificamente, neste artigo, a formação continuada, a especialização que os egressos realizaram.

$\mathrm{O}$ estudo de caso permite que o investigador aprofunde a sua visão em detalhes ou situações específicas. Segundo Bogdan e Biklen (1994, p. 89), “o estudo de caso consiste na observação detalhada de um contexto ou indivíduo, de uma única fonte de documentos ou de um acontecimento específico".

A amostra delimitada para a realização da pesquisa e aplicação do instrumento de coleta de dados foram os egressos da especialização, dos anos de 2015, 2016 e 2017. Os egressos da turma de 2015, em sua grande maioria, eram mulheres com mais de 26 anos que optaram pela docência por verem no magistério a possibilidade de uma carreira promissora. Para os demais anos investigados essa característica se manteve. Dos 32 egressos da especialização, 25 são do sexo feminino e 07 do sexo masculino. 
A turma de 2016 foi composta por 25 alunos, e também apresentou mais mulheres na especialização, 22 do sexo feminino e 03 do sexo masculino. A turma de 2017 apresentou 15 alunos, 08 do sexo feminino e 07 do sexo masculino. No Brasil, a carreira do magistério apresenta muitas mulheres atuando nos diferentes níveis e modalidades de educação e ensino, principalmente nos cursos superiores da área das ciências humanas e da saúde.

O total de egressos investigados foi de 72 alunos: 55 são do sexo feminino e 17 do sexo masculino. Das 55 mulheres, a formação inicial estende-se a diversas áreas de formação, como: nutrição, enfermagem, direito, jornalismo, estética, gastronomia, entre outras. Dos 17 homens que realizaram a especialização, a formação inicial foi realizada nas seguintes áreas: medicina, odontologia, direito, administração, engenharia, contabilidade, entre outras. Nenhum egresso realizou mestrado ou doutorado e 46 já tinham especialização na área da formação inicial.

Todos os sujeitos da pesquisa finalizaram a especialização e depois de um mês de formados responderam um questionário formativo que tinha 09 perguntas abertas e 06 perguntas fechadas que indagavam sobre a especialização realizada. O questionário foi elaborado no Google Docs e validado; foi enviado por e-mail para todos os egressos da especialização. O anonimato dos egressos ocorreu durante a coleta de dados e análise. O termo de consentimento livre esclarecido foi disponibilizado aos sujeitos da pesquisa juntamente com o questionário; todos os egressos envolvidos são maiores de 18 anos e aceitaram livremente participar da investigação. A pesquisa foi aprovada pelo comitê de Ética em pesquisa com o parecer número 1.801.624.

Os questionários respondidos foram recebidos por e-mail e codificados, de modo a permitir a sistematização da técnica de análise de conteúdo e a postura ética da pesquisa. $\mathrm{O}$ processo de codificação será melhor explicado na seção da análise dos dados e resultados.

\section{O processo de análise dos dados coletados}

A Análise de Conteúdo (AC), técnica utilizada para analisar os dados coletados, é composta por um conjunto de técnicas de análise das comunicações que utiliza procedimentos sistemáticos e objetivos da descrição do conteúdo de mensagens (BARDIN, 2011). Por sua vez, a AC permite que o pesquisador realize o processo de análise dos dados de diferentes ângulos: cada pesquisador aplica a técnica de acordo com a percepção que tem sobre o fenômeno investigado. Metodologicamente, esta pesquisa apoia-se nas postulações de Bardin 
(2011), depreendendo que as etapas da AC são constituídas por três fases: (a) pré-análise, (b) exploração do material e (c) tratamento dos resultados.

A pré-análise da técnica da AC, chamada também de leitura "flutuante", momento em que o pesquisador realiza a escolha e leitura dos documentos, a formulação das hipóteses, dos objetivos, da referenciação dos índices, da elaboração de indicadores e da preparação do material (BARDIN, 2011).

A fase de exploração do material compreende como "[...] a análise propriamente dita, não é mais do que a aplicação sistemática das decisões tomadas. Quer se trate de procedimentos aplicados manualmente ou de operações efetuadas por computador [...]" (BARDIN, 2011, p. 131). Nesta etapa, a autora considera que ocorre a codificação, enquanto organização sistemática, que se realiza para posteriormente classificar e categorizar. A fase de categorização é o processo que permite que os códigos sejam agrupados, segregados ou reagrupados com o objetivo de consolidar um significado (BARDIN, 2011).

Por fim, a fase de tratamento dos resultados é aquela onde "[...] os resultados brutos são tratados de maneira a serem significativos e válidos" [...] e o pesquisador “[...] tendo à sua disposição resultados significativos e fiéis, pode então propor inferências e adiantar interpretações a propósito dos objetivos previstos ou que digam respeito a outras descobertas inesperadas" (BARDIN, 2011, p. 131). Na próxima seção, apresenta-se a análise de dados dos 72 questionários respondidos.

\section{Análise dos dados e resultados}

Relativo à análise de dados dos 72 questionários a partir da $\mathrm{AC}$ na perspectiva de Bardin (2011), conforme descrita na seção do processo de análise dos dados coletados. A seguir, descreve-se a aplicação de cada etapa, preparação dos dados para análise (pré-análise), utilização do software Atlas Ti, codificação, categorização (exploração do material) e análise de conteúdo (tratamento dos resultados).

Fase 1 - Preparação dos dados para análise: todos os 72 questionários foram salvos em formato PDF e inseridos no software Atlas $\mathrm{Ti}^{4}$, com uma identificação para cada questionário respondido. Os questionários foram identificados da seguinte maneira: a sigla QF foi inserida em todos os questionários respondidos, juntamente com a expressão numérica 01, que

${ }^{4} \mathrm{O}$ software Atlas Ti foi adquirido na versão Mac para a análise qualitativa dos dados textuais; o software permite que a análise ocorra em gráficos, áudios e vídeos. O Atlas Ti possui ferramentas que ajudam na organização, sistematização e no gerenciamento dos dados. Possibilita a descoberta de fenômenos complexos, os quais, possivelmente, não seriam detectáveis por meio de uma simples leitura do texto e do tratamento manual dos dados. 
corresponde ao número de participantes da pesquisa. Foi inserida também a expressão numérica correspondente ao ano em que o egresso finalizou a especialização, 2015, 2016 e 2017.

Todas essas informações unidas formaram um código, QF012015, que apresenta o seguinte significado: questionário formativo do egresso 01 da especialização do ano de 2015. Para cada questionário respondido foi criada uma identificação com essas informações. Depois que os questionários foram identificados por um código, os mesmos foram adicionados ao software Atlas Ti para iniciar o processo de análise de dados.

Fase 2 - Exploração do material: As respostas do questionário formativo que ajudavam a responder o objetivo desta investigação foram selecionadas pelos pesquisadores no software Atlas Ti, com a finalidade de que essas fossem, em seguidas, codificadas com o auxílio do software.

Fase 3 - Codificação: Nesta etapa foram criados códigos, a fim de operacionalizar o processo de categorização. Os códigos são representados por um sistema de símbolos que permite a identificação de informações. Depois, realizou-se uma leitura crítica das respostas selecionadas, criando para essas, códigos que expressam a percepção do egresso em relação ao conhecimento adquirido na especialização. Conforme acontecia a leitura das respostas do questionário formativo os pesquisadores utilizavam também códigos já previamente criados. Para tanto, nesta investigação foram criados 52 códigos.

Fase 4 - Categorização: Nesta etapa visou-se à união, ou seja, a formação de conjuntos de códigos por incidência e semelhança, ação que permite agrupar dados e consolidar um significado para tais informações. Depois que todas as respostas do questionário formativo foram codificadas e categorizadas visualizou-se no software Atlas Ti os códigos que tiveram maior incidência e semelhança diante dos resultados das respostas analisadas.

Fase 5 - Análise de Conteúdo: Os códigos com maior incidência e semelhança foram submetidos a quatro procedimentos adicionais, por meio da Análise de Conteúdo (BARDIN, 2011), sendo esses: a) leitura detalhada dos resultados encontrados; b) análise reflexiva por parte dos pesquisadores nos resultados das respostas do questionário formativo; c) identificação e criação dos grupos de categorias de convergência, para fins de consolidação de um significado; e d) criação de categorias de significados.

As categorias emergentes constituíram-se como indicadores, as quais possibilitaram compreender as incidências semelhantes presentes nas respostas dos egressos do questionário formativo. Para isso, os pesquisadores foram em busca do significado e do sentido das respostas dos participantes e estavam interessados também em saber a intensidade do 
aparecimento dos significados lógicos semânticos, para isso, decidimos quantificar as frequências absolutas e relativas das respostas.

A seguir, são apresentados quadros que apresentam três elementos textuais identificados nas respostas do questionário formativo que foram utilizados como exemplos para a criação das categorias, diante da quantidade de incidência e semelhança que o código teve. Para essa pesquisa, a análise de conteúdo aconteceu em 01 pergunta do questionário formativo que ajuda os pesquisadores a responderem o objeto de investigação.

A pergunta 13 do questionário formativo realizava o seguinte questionamento: Quais conhecimentos adquiridos na especialização diante do seu ponto de vista você acha essencial para a formação de um professor? Justifique a sua resposta.

$\mathrm{O}$ código que apresentou maior incidência para essa pergunta foi "Conhecimento Pedagógico", com 55 incidências. Conforme o Quadro 02, apresenta-se as categorias que foram criadas a partir do código analisado.

Quadro 02 - Alguns resultados explicitados nas pesquisas para justificar o código conhecimento pedagógico

\begin{tabular}{|c|c|}
\hline CATEGORIAS & \\
\hline Para ensinar - Metodologias de Ensino & $\begin{array}{l}\text { Quantidade de incidência } \\
\text { que o código teve: } 09\end{array}$ \\
\hline $\begin{array}{l}\text { "Durante a especialização percebi que o conhecimento pedagógico é } \\
\text { fundamental para ser professor, estudar as teorias da educação, didática, as } \\
\text { concepções de ensino são conhecimentos fundamentais para ensinar, nas } \\
\text { aulas os professores utilizaram muitas metodologias ativas, e estudamos isso } \\
\text { na pós, acho que a metodologia do ensino é a chave para ser um bom } \\
\text { professor". }\end{array}$ & $\begin{array}{lll}\text { Resposta } & \text { do } & \text { Egresso } \\
\text { QF182015 } & & \end{array}$ \\
\hline $\begin{array}{l}\text { "Depois que finalizei a especialização percebi que o conhecimento } \\
\text { pedagógico é a base para qualquer professor em qualquer nível de ensino. Ele } \\
\text { é o elemento essencial para a formação de um professor. Sua metodologia de } \\
\text { ensino deve estar cheia de conhecimentos pedagógicos para que o professor } \\
\text { possa realmente ensinar". }\end{array}$ & $\begin{array}{lll}\text { Resposta } & \text { do } & \text { Egresso } \\
\text { QF032016 } & & \end{array}$ \\
\hline $\begin{array}{l}\text { "Sem sombra de dúvida, o conhecimento pedagógico, sem ele o professor não } \\
\text { ensina. A maneira que ele direciona o conhecimento por meio da sua } \\
\text { metodologia faz a diferença, pudemos vivenciar e presenciar diferentes } \\
\text { metodologias de ensino, os professores falaram muito sobre as metodologias } \\
\text { ativas". }\end{array}$ & $\begin{array}{lll}\text { Resposta } & \text { do } & \text { Egresso } \\
\text { QF112017 } & & \end{array}$ \\
\hline Para estar em Sala de Aula & $\begin{array}{l}\text { Quantidade de incidência } \\
\text { que o código teve: } 15\end{array}$ \\
\hline $\begin{array}{l}\text { "Aprendi muito na especialização, não imagina que para ser professora eu } \\
\text { teria que ter muitos conhecimentos pedagógicos para estar em sala de aula. } \\
\text { Sem esses conhecimentos o professor não faz diferença no processo de ensino } \\
\text { e aprendizagem". }\end{array}$ & $\begin{array}{lll}\text { Resposta do } & \text { Egresso } \\
\text { QF252015 } & & \end{array}$ \\
\hline $\begin{array}{l}\text { "Os professores da especialização destacaram muito a importância do } \\
\text { professor ter conhecimentos pedagógicos para embasar a prática educativa. } \\
\text { Estudando, percebi que os conhecimentos pedagógicos são primordiais para } \\
\text { estar em sala de aula e realmente ensinar e não ficar só lendo slides para os } \\
\text { alunos". }\end{array}$ & $\begin{array}{ll}\text { Resposta do } \\
\text { QF082016 }\end{array}$ \\
\hline $\begin{array}{l}\text { "O conhecimento pedagógico, sem dúvida, sem ele o professor terá } \\
\text { dificuldades para estar em sala de aula, esse conhecimento permite que o }\end{array}$ & $\begin{array}{llr}\text { Resposta do } & \text { Egresso } \\
\text { QF132017 } & & \\
\end{array}$ \\
\hline
\end{tabular}




\begin{tabular}{|l|lc|}
\hline professor esteja em sala de aula sabendo o que ele irá fazer". & \\
\hline Para poder vivenciar a Docência & $\begin{array}{l}\text { Quantidade de incidência } \\
\text { que o código teve: 31 }\end{array}$ \\
\hline $\begin{array}{l}\text { "Sempre quis ser professora, mas a vida me levou para o campo da } \\
\text { Administração e depois que terminei a minha especialização em recursos } \\
\text { humanos eu decidi ser professora do curso de Administração. Eu nunca } \\
\text { imaginei que a profissão professor querer uma série de conhecimentos } \\
\text { pedagógicos para vivenciar à docência, o processo de ensino e os desafios } \\
\text { presentes no contexto universitário. Um diferencial da pós, foi me permitir } \\
\text { realizar estágio com alguns dos professores do curso de administração para } \\
\text { pode viver o que é ser um professor universitário". }\end{array}$ & \\
\hline $\begin{array}{l}\text { "Muitos são os conhecimentos, mas o conhecimento pedagógico eu elejo } \\
\text { como sendo o principal. Sem o conhecimento pedagógico, o professor não }\end{array}$ & QF162016 \\
terá base para exercer a docência, vivenciar o dia a dia do ato de ensinar e \\
saber o que fazer quando as dificuldades surgem".
\end{tabular}

Fonte: Autoria própria

No quadro 02 foi possível identificar que a categoria "Conhecimentos Pedagógicos" apresentou 55 incidências a partir das respostas dos egressos que responderam o questionário formativo. Infere-se assim que o número de incidência reforça a importância que o conhecimento pedagógico tem para a formação de um professor. Pelas respostas dos egressos percebemos que a especialização proporcionou conhecimentos pedagógicos relacionados à formação docente que são fundamentais para o exercício da profissão.

Assim, a formação de professores está atrelada aos quesitos de desenvolvimento da identidade profissional e da construção da sua prática, é compreendida pela construção de conhecimento adquirido que acontece na formação, conhecimento este que recebe influência do contexto social, político, econômico e, principalmente, do formador, ou seja, "a especificidade da profissão docente está no conhecimento pedagógico" (IMBERNÓN, 2011, p. 30).

O conhecimento pedagógico é o que diferencia o professor de outros profissionais. Quando o docente alia a sua formação de base, a sua formação inicial no caso dos bacharéis, com o conhecimento pedagógico adquirido, ele adquire uma identidade docente. Gauthier (1998) e Imbernón (2011) defendem que o conhecimento pedagógico diferencia o professor e faz diferença na formação, assim como no seu desenvolvimento profissional.

Desta forma, foi possível identificar também pelas respostas dos egressos que os conhecimentos pedagógicos permitem vivenciar a docência, conhecer a realidade profissional enquanto aluno no processo formativo e para futuramente exercer a profissão. Reiteramos que 
os conhecimentos pedagógicos permitem que o aluno possa conhecer a sua realidade profissional diante da sua complexidade a partir do estágio supervisionado, permitindo que ele utilize dos seus conhecimentos pedagógicos construídos na formação para buscar soluções diante dos desafios que aparecem na prática profissional e no contexto de ensino.

A oportunidade de vivenciar a docência, seja ela formação inicial ou continuada, a partir das respostas dos egressos, mostrou ser um diferencial para o processo formativo para os bacharéis. Atualmente, muitas são as pesquisas que investigam e reivindicam melhorias para os programas de formação de professores que oportunizam vivenciar a docência, como o Programa Institucional de Bolsas de Iniciação à Docência (PIBID).

\section{Considerações finais}

Este artigo teve como objetivo analisar as percepções dos egressos em relação ao conhecimento adquirido a partir de uma especialização para a formação de professores. A partir das categorias que emergiram da análise de conteúdo realizada nas respostas do questionário formativo foi possível identificar que os egressos elegeram o conhecimento pedagógico como sendo um saber imprescindível para a formação docente.

Os bacharéis que realizaram a especialização apontaram outros conhecimentos como essenciais para formação de um professor, como: os relacionados à especificidade da aprendizagem, o uso de tecnologias no processo de ensino e aprendizagem, inclusão de alunos com necessidades especiais, entre outros, mas esses conhecimentos não apresentaram incidência suficiente para se tornar uma categoria de análise.

Temos o entendimento de que há uma série de conhecimentos que são necessários e fazem parte da formação de professores, bem como um conhecimento específico da identidade docente, o conhecimento pedagógico, que se constitui da ação ou do resultado de ensinar.

A partir da análise realizada foi possível identificar que o conhecimento pedagógico é essencial para poder vivenciar a docência, conhecimento este que permite estar diante do processo de ensino e aprendizagem, conhecer e intervir no contexto educativo e buscar respostas para os desafios presentes na docência.

As respostas dos egressos enfatizaram que o conhecimento pedagógico é importante para que o professor possa estar em sala de aula, contexto este que se apresenta complexo e dinâmico. Identificou-se também que o conhecimento de diferentes metodologias de ensino faz parte do conhecimento pedagógico de um professor. 
A pesquisa realizada contribui ao campo da formação de professores, pois reafirma que o conhecimento pedagógico é o conhecimento primordial para formar um professor. Este conhecimento está recheado de por uma série de elementos que constitui a docência, visto na investigação pelas categorias, as metodologias de ensino, o conhecimento para estar em sala de aula e vivenciar a docência.

Esses elementos que constitui o conhecimento pedagógico podem colaborar para a organização do currículo dos cursos de formação inicial e continuada de professores e da sua utilidade para o exercício da profissão.

\section{REFERÊNCIAS}

BARDIN, Laurence. Análise de Conteúdo. São Paulo: Edições 70, 2011.

BOGDAN, Robert.; BIKLEN, Sari Knopp. Investigação Qualitativa em Educação. Porto: Editora Porto, 1994.

CHIZZOTTI, Antonio. Pesquisa qualitativa em ciências humanas e sociais. Petrópolis, RJ: Vozes, 2006.

CRESWELL, John Went. Investigação qualitativa e projeto de pesquisa: escolhendo entre cinco abordagens. 3. ed. Porto Alegre: Penso, 2014.

FERREIRA, Jacques de Lima. A complexa relação entre teoria e prática pedagógica na formação de professores. In: FERREIRA, Jacques de Lima (Org.). Formação de professores: teoria e prática pedagógica. Petrópolis, RJ: Vozes, 2014, p. 33-49.

GAUTHIER, Clermont. Por uma teoria da pedagogia: pesquisas contemporâneas sobre o saber docente. Ijuí, RS: Editora Unijuí, 1998.

IMBERNÓN. Francisco. Formação docente e profissional: formar-se para a mudança e a incerteza. 7. ed. São Paulo: Cortez, 2011.

NÓVOA, António. Professores: imagens do futuro presente. Lisboa: Educa, 2009.

PIMENTA, Selma Garrido. Formação de professores: identidade e saberes da docência. In: PIMENTA, Selma Garrido. (Org.). Saberes pedagógicos e atividade docente. 3. ed. São Paulo: Cortez, 2002. p. 15-34.

SAVIANI, Dermeval. Os saberes implicados na formação do educador. In: BICUDO, Maria Aparecida. (Org.). Formação do educador: dever do Estado, tarefa da Universidade. São Paulo: UNESP, 1996, p. 45-59.

SILVA, Carla Odete Balestro. Ad-mirando o professor de formação técnica: o fazer-se docente no encontro com o Proeja em dois campi do IFSUL. 2011. 256 f. Dissertação 
(Mestrado em Educação), Universidade Federal do Rio Grande do Sul, Programa de Pósgraduação em Educação, Porto Alegre, 2011.

TARDIF, Maurice.; LESSARD, Claude.; LAHAYE, Louise. Esboço de uma problemática do saber docente. Porto Alegre: Teoria e Educação, 1991.

TARDIF, Maurice; GAUTHIER, Clermont. O professor como "ator racional": que racionalidade, que saber, que julgamento? In: PAQUAY, Léopolf; PERRENOUD, Philipe; ALTET, Marguerite; CHARLIER, Evelyne (Orgs.). Formando professores profissionais: Quais estratégias? Quais competências? 2. ed. Porto Alegre: Artes Médicas, 2001. p. 185-210.

TARDIF, Maurice. Saberes docentes e formação profissional. 2. ed. Petrópolis: Vozes, 2002.

\section{Como referenciar este artigo}

FERREIRA, Jacques de Lima.; BEHRENS, Marilda Aparecida.; TEIXEIRA, Alexandre Marinho. Formação de professores para atuar no ensino superior, tecnológico e técnico. Revista Ibero-Americana de Estudos em Educação, Araraquara, v. 14, n. 1, p. 123-137, jan./mar., 2019. E-ISSN: 1982-5587. DOI: 10.21723/riaee.v14i1.11132

Submissão: $28 / 02 / 2018$

Revisões requeridas: 13/05/2018

Aprovação final: 10/09/2018 